\title{
Anabases
}

ANABASES Traditions et réceptions de l'Antiquité

26 | 2017

Varia

Laurence BAURAIN-REBILLARD (éd.), Héros grecs à travers le temps : autour de Persée, Thésée, Cadmos et Bellérophon

\section{Carine Giovénal}

\section{OpenEdition}

Journals

Édition électronique

URL : http://journals.openedition.org/anabases/6243

DOI : $10.4000 /$ anabases. 6243

ISSN : 2256-9421

Éditeur

E.R.A.S.M.E.

Édition imprimée

Date de publication : 1 novembre 2017

Pagination : 223-225

ISSN : 1774-4296

\section{Référence électronique}

Carine Giovénal, «Laurence bauRaIn-Rebillard (éd.), Héros grecs à travers le temps : autour de Persée, Thésée, Cadmos et Bellérophon », Anabases [En ligne], 26 | 2017, mis en ligne le 01 novembre 2017, consulté le 19 janvier 2021. URL : http://journals.openedition.org/anabases/6243 ; DOI : https:// doi.org/10.4000/anabases.6243

Ce document a été généré automatiquement le 19 janvier 2021.

(c) Anabases 


\title{
Laurence BAURAIN-REBILLARD (éd.), Héros grecs à travers le temps: autour de Persée, Thésée, Cadmos et Bellérophon
}

\author{
Carine Giovénal
}

\section{RÉFÉRENCE}

Laurence BAURAIN-REBILLARD (éd.), Héros grecs à travers le temps : autour de Persée, Thésée, Cadmos et Bellérophon, Actes du colloque de Metz, 28-30 mai 2015, Centre de recherches universitaires lorrain d'Histoire, n58, Metz, Université de Lorraine, 2016, 382 p., 25 euros/ ISBN 2-85730-065-4.

1 Les figures les plus riches, dans les mythes et la pensée des anciens Grecs, étaient les héros, et ce sont eux aussi qui, plus que les dieux, ont capté l'intérêt des auteurs et des artistes au-delà de l'Antiquité. Alors que le plus célèbre d'entre eux, Héraclès, est élevé au rang de dieu, Persée, Thésée, Cadmos et Bellérophon s'ancrent dans un territoire dont chacun devient le héros national, jouant un rôle majeur dans la cohésion et l'identité des groupes qui les ont adoptés. Le volume regroupe quinze contributions consacrées à ces quatre personnages avec pour objectif d'étudier leur transmission à travers les siècles, les contextes et les formes d'expression. Dans une perspective diachronique couvrant plus de trois millénaires, de l'Antiquité à nos jours, ces articles de littéraires, d'historiens, d'archéologues, d'historiens de l'art font le point sur des époques et sources différents en se focalisant généralement sur un héros en particulier.

2 Les six premières études concernent Persée. Claude Baurain analyse le culte rendu à Mycènes au héros et met en évidence les rivalités politiques $\mathrm{du} \mathrm{VIII}^{\mathrm{e}} \mathrm{au} \mathrm{v} \mathrm{v}^{\mathrm{e}}$ siècle avant J.$C$; puis Jean-Pierre Darmon élargit l'enquête à l'ensemble du bassin méditerranéen par l'étude des mosaïques consacrées à Persée dans l'espace domestique. L'accent est mis 
sur la libération d'Andromède avec l'étude du tableau de Piero di Cosimo par Emmanuel Ussel. Anne-Elisabeth Spica se penche ensuite sur la figure du "nouveau Persée " apparue avec la culture humaniste et les guerres de religion, alors que le héros grec, grâce à la "plastique mythologique ", incarne le roi chrétien pourfendeur du dragon. Daniela Gallo s'intéresse aux œuvres sculptées du xvIII siècle, puis Jeanne Demarolle clôt la série avec le tableau Persée tuant le dragon de Félix Vallotton en 1910, œuvre qui prend le contre-pied de la tradition en représentant Andromède et Persée entièrement humanisés et menacés par... un crocodile.

Avec le héros thébain Cadmos, Karin Mackowiak se penche sur le mythe réinterprété $\mathrm{du}$ point de vue athénien au $\mathrm{v}^{\mathrm{e}}$ siècle avant $\mathrm{J}$.-C, notamment par une forte mise en valeur d'Athéna. La seconde moitié du volume se consacre à Thésée : la vie du héros athénien selon les céramistes du $v^{e} s$ av. J.-C. (H. A. Shapiro), l'étude par Laurence Baurain-Rebillard du discrédit moral qui s'attache à Thésée en contraste avec l'image positive de Persée, puis la réception de ce héros dans le monde romain à travers la littérature ovidienne et les représentations plastiques, gemmes, art funéraire, fresques (M. Galinier). On retrouve ensuite l'époque moderne avec Céline Bohnert et Judith Le Blanc qui s'intéressent aux tragédies de Lully mettant en scène Thésée, Persée, Cadmos et Bellérophon, tous quatre assimilés à Louis XIV dont il s'agissait d'exalter la grandeur - non sans préciser que ce genre lyrique a suscité sa parodie qui ridiculise les héros antiques; moins d'un siècle plus tard, Vanloo expose une peinture de Thésée allégorie de Louis XV (P.-F. Bertrand). Enfin, les deux dernières contributions se consacrent au réinvestissement de la culture classique par les auteurs contemporains d'œuvres pour la jeunesse : sept ouvrages dédiés à la vie de Thésée montrent comment ce héros reste un sujet littéraire propre à ouvrir la réflexion sur le monde d'aujourd'hui (A. Eissen), et P.-A Colombani s'interroge sur la continuité entre héros grecs et super-héros au cinéma, dans les jeux vidéo et les comics.

4 Si les figures de Cadmos et Bellérophon restent dans l'ombre des deux « géants » que sont Persée et Thésée, on se plonge cependant avec un vif intérêt et un plaisir croissant dans cet ouvrage où se croisent littérature, musique, arts plastiques et médias contemporains. On appréciera notamment le choix de la perspective diachronique qui jette un pont entre l'Antiquité et les modes d'expression d'aujourd'hui, et nous montre comment l'archétype hérö̈que n'a cessé de se reconfigurer pour s'adapter aux imaginaires de chaque époque.

\section{AUTEURS}

\section{CARINE GIOVÉNAL}

Université François-Rabelais de Tours

c.giovenal@hotmail.com 